\title{
Determining the Incidence of Adult Fractures: How Accurate Are Emergency Department Data?
}

\author{
Stuart A. Aitken, Mark A. Rodrigues, Andrew D. Duckworth, \\ Nicholas D. Clement, Margaret M. McQueen, and Charles M. Court-Brown
}

The Orthopaedic Trauma Unit, Department of Orthopaedics, Royal Infirmary of Edinburgh, Little France, Edinburgh EH16 4SU, UK

Correspondence should be addressed to Stuart A. Aitken, stuart.aitken@nhs.net

Received 2 April 2012; Revised 10 May 2012; Accepted 16 May 2012

Academic Editor: Huibert Burger

Copyright $\odot 2012$ Stuart A. Aitken et al. This is an open access article distributed under the Creative Commons Attribution License, which permits unrestricted use, distribution, and reproduction in any medium, provided the original work is properly cited.

\begin{abstract}
Various research methods have been used to obtain skeletal fracture data and report the incidence of fractures. A large number of British studies have used data collected in emergency departments, and not data derived from orthopaedic units. We hypothesised that fracture data will differ depending upon the methodology employed to capture it. Two commonly used sources of fracture data at our institution were compared, (the Emergency Department (ED) database and the Orthopaedic Trauma Unit (OTU) database), using a cohort of adult patients from our defined population as the study sample. We performed univariate analyses to identify differences between groups with accurate and inaccurate ED fracture diagnoses. We then performed a binary logistic regression analysis to determine the best predictors of diagnostic accuracy. In one year, 7,449 patients were referred to the OTU. Three-quarters were referred with fractures. The overall false positive fracture referral rate was $25 \%$. Several fracture subtypes were commonly overdiagnosed in the ED. Regression analysis showed that patient age, patient gender, and the seniority of the referring clinician were independently predictive of an accurate fracture diagnosis. We suggest that studies making use of ED fracture data may potentially overestimate the incidence of adult fractures.
\end{abstract}

\section{Introduction}

The systematic collection and analysis of skeletal fracture data is the essence of fracture epidemiology. Its application to clinical practice allows clinicians to compare affected with unaffected patient groups, determine definable and preventable characteristics that predispose to skeletal fracture, and ensure the provision of appropriate treatment strategies.

Cummings et al. [1], in their review of the methodological challenges facing all injury epidemiologists, identified several key areas including the definition and classification of injuries and the importance of defining the population at risk. The analysis of fracture data can only occur if fractures are identified accurately. This process relies upon the ability of clinicians to make clinical judgements and accurately interpret standard plain radiographs. It has been suggested that experienced clinicians are able to identify fractures with greater accuracy than those less experienced $[2,3]$. In adult patients, only a small number of studies have analysed the incidence of fractures in a given population. Reported rates vary considerably, with Donaldson et al. [4] suggesting a rate four times higher than Brinker and O'Connor [5] (36.0/1000/yr versus 8.5/1000/yr).

It is highly likely that variation exists between populations in different countries, and between regions within the same country, but we feel the reported differences in adult fracture incidence in the literature are unlikely to be explained by population demographics alone. Notably, many studies have used different research methods in obtaining skeletal fracture data.

In four studies the fracture diagnoses were made from radiographs examined by orthopaedic specialists and radiologists, and the authors reported similar results (CourtBrown et al., 13.7/1,000/yr [6]; Court-Brown and Caesar, 11.2/1000/yr [7]; Singer et al., 13.8/1000/yr [8]; Donaldson et al., 9.1/1000/yr [9]). Three investigations obtained fracture 
data from emergency department databases and coding systems, and reported notably higher rates of fracture (Johansen et al., 21.1/1000/yr [10]; Sahlin, 22.8/1000/yr [11]; Fife and Barancik, 21.0/1000/yr [12]). Donaldson et al. employed a patient questionnaire strategy to determine fracture incidence (36.0/1000/yr [4]). Brinker and O'Connor obtained medical insurance company data (8.5/1000/yr [5]), while van Staa et al. made use of the United Kingdom (UK) general practice research database (GPRD) and reported a fracture incidence of $10.3 / 1000 / y r$ [13].

In order to investigate the discrepancy in adult fracture incidence between studies, a prospective cohort study was undertaken at our institution. The ascertainment of fractures in the emergency department (ED) was compared with that of the orthopaedic trauma unit (OTU) in the same cohort of adult patients. Our primary research objective was to test our hypothesis that a difference exists between the ED and the OTU fracture databases. Our secondary objective was to identify predictors of ED diagnostic accuracy by examining variables such as patient age, patient gender, fracture subtype, and the grade of referring ED clinician.

\section{Materials and Methods}

2.1. Participants. The study was conducted with the approval of the South East Scotland research ethics service. The Royal Infirmary of Edinburgh (RIE) serves a defined adult population. All adult patients presenting to the ED, with onward referral to the OTU, were prospectively recorded for one year (July 2007 to June 2008). This is the only OTU for a population of 545,081 adults (52\% women). Population data were obtained from the General Register Office for Scotland [14].

All patients in Edinburgh aged less than 13 years, and a proportion aged less than 15 years, are treated at a separate paediatric institution. Therefore only patients aged 15 years or older were included. Patients residing out with the defined catchment area of the RIE and those referred from other institutions were excluded. All patient records in the ED are held electronically and can be accessed and reviewed as required. Details of OTU fracture clinic review are also held electronically. Patients for whom no ED notes or fracture clinic notes could be obtained were excluded, as were those for whom the grade of referring ED clinician was unclear. Patients who failed to attend fracture clinic or chose to cancel their appointment were also excluded.

Patients with fractures requiring immediate admission and inpatient treatment were deemed unsuitable for inclusion in this study. Such patients were reviewed by the ED and OTU clinicians simultaneously, which limited the identification of any discrepancy in fracture ascertainment. In contrast, patients requiring outpatient OTU fracture treatment were rarely reviewed by the OTU clinician prior to fracture clinic attendance. These patients therefore made up the study population. In order to pick up possible misdiagnoses, all fracture and nonfracture patient referrals were included in the analysis.

2.2. Classification of Injury. Demographic data were recorded for all patients referred to the OTU fracture clinic.
ED diagnostic data were obtained from the electronic patient record, and details of the ED attendance, clinicians' examination, provisional diagnosis and reason for referral were recorded. Patient injury types were defined as fractures, dislocations, soft tissue injuries, musculotendinous ruptures, wounds, or other injury types. Fracture subtypes were determined, and are detailed in Section 3.

2.3. Data Handling. The grade of the referring ED clinician was recorded. On presenting to the $\mathrm{ED}$, patients were seen and referred by a nurse practitioner $(N P)$, junior grade physician (SHO/FY/ST1-2), middle grade physician (SpR/ST3-6), or consultant grade physician (Cons). In cases where the patient had been reviewed by a number of ED clinicians prior to referral, the grade of the most senior clinician was recorded. In cases where the OTU clinician had been asked to review the patient prior to referral, the grade was recorded as "OTU".

The final OTU diagnosis was made by the OTU clinician in fracture clinic, with or without the additional information provided by the radiology report of accompanying plain radiographs. In cases where the OTU diagnosis remained unclear pending further review or repeat imaging, recording of the definitive diagnosis was deferred until such time as the diagnosis could be confidently made.

In order to test the hypothesis that a difference in fracture ascertainment exists between the ED and the OTU at our institution, we defined a "correct" ED diagnosis (true positive case) as one where both the injury type and fracture subtype agreed with the final OTU diagnosis. Any diagnostic discrepancy was deemed a false positive. In particular, when the ED diagnosis of "fracture" injury type was correct, but the fracture subtype was incorrectly diagnosed, this was deemed a false positive. The recording of true and false negatives was not possible, as uninjured patients were not referred for OTU assessment.

2.4. Statistical Analysis. No estimate of sample size was made on the basis of assumptions about the primary research objective. A twelve month sample of convenience was used. For the purposes of statistical analysis, multiple events (multiple injuries at presentation; recurrent injury in the same patient over time) were treated as distinct entities.

2.5. Primary Research Objective. Continuous data were presented in terms of the median and range. Median values between groups were compared using the Mann-Whitney $U$ (MWU) test. Groups of categorical variables were compared using the chi-square test. A two-tailed $P$ value of $<0.05$ was considered statistically significant. The positive predictive value (PPV) of ED diagnosis was calculated by dividing the number of true positive (TP) diagnoses by the number of true positive plus false positive (FP) diagnoses, expressed as a percentage according to the following:

$$
\mathrm{PPV}=\frac{\mathrm{TP}}{(\mathrm{TP}+\mathrm{FP})} \times 100
$$

2.6. Secondary Research Objective. To investigate the potential effect of patient age, patient gender, injury type, fracture 


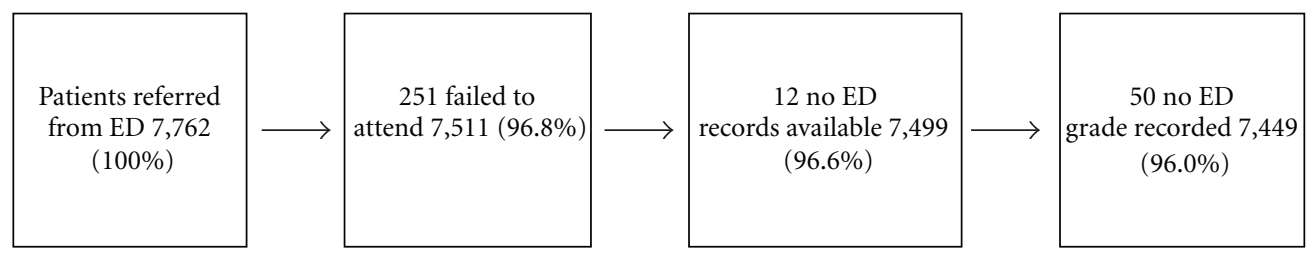

Figure 1

TABLE 1: The PPV of a correct ED diagnosis according to the grade of referring ED clinician.

\begin{tabular}{lccccc}
\hline ED grade & Total $(n)$ & Correct $(n)$ & Incorrect $(n)$ & PPV $(\%)$ & 82.8 \\
\hline Consultant & 437 & 362 & 75 & 221 & 80.6 \\
SpR/StR 3+ & 1,142 & 921 & 518 & 76.4 & 0.012 \\
SHO/StR 1-2 & 2,195 & 1,677 & 808 & 76.4 & 0.019 \\
NP & 3,425 & 2,617 & 16 & 93.6 & 0.030 \\
OTU & 250 & 234 & 1,638 & 77.5 & -002 \\
All grades & 7,449 & 5,811 & & & -0001 \\
\hline
\end{tabular}

** Chi-square tests.

TABLE 2: The PPV of a correct ED diagnosis according to injury type diagnosis, made by the referring ED clinician, and arranged in order of descending percentage PPV.

\begin{tabular}{lccccc}
\hline ED injury type & Total & Correct $(n)$ & Incorrect $(n)$ & PPV $(\%)$ & 100 \\
Wounding & 17 & 17 & 0 & 98.5 & 0.028 \\
STI & 854 & 841 & 13 & 35 & 92.4 \\
Dislocation & 464 & 429 & 30 & 82.6 & $<0.0001$ \\
Rupture & 172 & 142 & 1,491 & 73.8 & 0.145 \\
Fracture & 5,695 & 4,204 & 65 & 73.7 & $<0.0001$ \\
Other & 247 & 182 & & 0.068 \\
\hline
\end{tabular}

** Chi-Square tests.

subtype, and grade of referring ED clinician on the chance of a correct ED diagnosis, two binary logistic regression analyses were performed. Only those variables that proved nearly significant $(<0.01)$ or significant $(<0.05)$ after univariate analyses were entered into the regression analyses. The first regression analysis was performed to determine the best predictors of a correct ED injury type diagnosis, and the second to determine predictors of a correct ED fracture subtype diagnosis. The regression models produced an odds ratio for each of the independent variables, the $\operatorname{Exp}(\mathrm{B})$, along with the accompanying $95 \%$ confidence interval.

\section{Results}

3.1. Patients. In one year, 7,762 patients were referred from ED to the OTU fracture clinic. Two-hundred and fiftyone patients either cancelled their appointment or failed to attend for review. In twelve cases, no ED records were available. In fifty cases, the grade of the referring ED clinician was unclear. The patient pathway is summarised in the flow diagram (see Figure 1).

3.2. Primary Research Objective. After exclusions, 7,449 patients had an ED diagnosis and OTU diagnosis available for comparison. The overall PPV for an ED diagnosis was 78.0\% (5,811 true positives and 1,638 false positives). Patients attributed a false positive ED diagnosis (age $33 \mathrm{yrs}, 20-52 \mathrm{yrs}$ ) were significantly younger than those given a true positive ED diagnosis (age $38 \mathrm{yrs}, 22-58 \mathrm{yrs}),(P<0.0001$, MWU).

Male patients accounted for 4,127 (55.4\%) of 7,449 ED referrals. The PPV of a correct ED diagnosis was higher in men $(\mathrm{PPV}=79.0 \%)$ than in women $(\mathrm{PPV}=76.8 \%),(P=$ $0.023)$. A correct ED diagnosis was highest when the patient had been reviewed by the OTU clinician in the ED prior to referral (Table 1). However, the OTU clinician referred the fewest number of patients. Senior ED clinicians (Consultants and $\mathrm{SpRs}$ ) were more likely to refer a patient with a correct diagnosis than junior colleagues (SHOs and NPs). Junior ED clinicians made 5,620 (75.4\%) referrals to the OTU.

Seventeen patients were referred to fracture clinic with an ED diagnosis of soft tissue wounding. All had been correctly diagnosed (Table 2). "Other" diagnoses accounted for 247 referred cases, and contained a wide variety of conditions that did not meet the inclusion criteria for another injury type category. Commonly encountered cases included suspected soft tissue infection, postoperative pain and swelling, joint or limb pain in the absence of trauma, exacerbations of arthropathies, and the presence of symptomatic orthopaedic implants. 
Traumatic joint dislocations were accurately diagnosed by the ED clinician. The three commonest dislocation final diagnoses were those affecting the glenohumeral joint $(n=$ $229)$, fingers or thumb $(n=90)$, and the acromioclavicular joint $(n=44)$.

Musculotendinous rupture was diagnosed in $172 \mathrm{pa}-$ tients, but in thirty patients the OTU diagnosis differed from this. The ascertainment of this injury type was less accurate than that of a traumatic dislocation (PPV 82.6\% versus $92.4 \%$ ). The three commonest rupture final diagnoses involved the Achilles/gastrocnemius complex $(n=69)$, the extensor apparatus in the fingers $(n=66)$, and the ulnar collateral ligament of the thumb $(n=5)$. Of note, patients with extensor mechanism ruptures of the knee were all admitted to the OTU for operative treatment. Where a diagnostic discrepancy was apparent, this was most commonly due to referred ruptures of the Achilles' tendon receiving an OTU diagnosis of soft tissue injury.

Emergency department clinicians diagnosed 854 soft tissue injuries with a PPV of $98.5 \%$. The majority of soft tissue injury referrals were knee injuries $(n=655)$ directed towards dedicated acute knee clinics. Soft tissue injury to the shoulder $(n=72)$ and ankle $(n=23)$ were also commonly encountered.

Three-quarters of ED patient referrals to the OTU fracture clinic arrived with a diagnosis of skeletal fracture. Of 5,695 patients referred with a fracture, 1,491 (26.2\%) were attributed a false positive diagnosis. A small number had been miscoded as fractures from a different anatomical region. The majority of false positive diagnoses received an OTU diagnosis of soft tissue injury. Eight fracture subtype diagnoses were significantly better diagnosed than the average, while a further eight were diagnosed with less accuracy (Table 3).

3.3. Secondary Research Objective. To identify significant predictors of accurate ED diagnoses and injury ascertainment, all independent variables that had proven nearly significant $(<0.01)$ or significant $(<0.05)$ after univariate analysis were entered into binary logistic regression models. The first model aimed to identify predictors of a correct ED injury type diagnosis, and the results are shown in Table 4.

The second regression model identified predictors of a correct ED fracture subtype diagnosis. Patient age $(\operatorname{Exp}(\mathrm{B})$ 1.01 , CI 1.01-1.02), male gender $(\operatorname{Exp}(B) 1.17$, CI 1.01$1.36)$, SHO grade clinician $(\operatorname{Exp}(B) 0.76$, CI $0.66-0.88)$ and ortho grade clinician $(\operatorname{Exp}(B) 3.60, C I$ 2.00-6.48) remained significantly predictive variables.

\section{Discussion}

At our institution, we discovered a significant difference between the ascertainment of skeletal fractures in adult outpatients when comparing ED and OTU data sources. The PPV of a correct ED fracture diagnosis was $73.8 \%$. Several common fracture subtype diagnoses had PPVs that were less accurate than the average (fractures of the carpus, proximal tibia, proximal radius, calcaneus, talus, and midfoot).
Regression analysis showed that patient age, patient gender, and the grade of referring ED clinician were independently predictive of a correct fracture diagnosis.

These results suggest that studies on the epidemiology of adult fractures which use ED data sources may overestimate adult fracture incidence. The published studies using ED methodology [10-12] have reported adult fracture incidence to be $50 \%$ greater than studies involving orthopaedic data collection [6-9]. At our institution, two-thirds of adult fractures encountered were treated on an outpatient basis during the study period, and the number of outpatient fractures has been overestimated by $26.2 \%$ (the overall false positive rate).

We accept this investigation has been limited to outpatient OTU referrals, and has not investigated the potential discrepancy between inpatient admission and discharge diagnoses. However, a systematic review of inpatient discharge coding accuracy in the UK [15] concluded that discharge coding performed by administrative staff is on average highly accurate. Furthermore, at our institution all inpatient fracture coding is routinely performed by OTU clinicians rather than administrative staff. Further work will focus on identifying a diagnostic discrepancy for inpatient fracture data.

These results apply to our institution and the Edinburgh population. They may not be applicable to populations whose social demographics vary substantially from our own, but we believe they will apply to many similar regions. Additionally, differences in staffing of EDs between regions will also affect the discrepancy between ED and orthopaedic fracture ascertainment. We accept that in clinical practice senior clinicians are called upon to review more severe or difficult cases, and that this may have an effect on the accuracy of referral. Notably, nurse practitioner clinicians performed equally as well as junior ED doctors, further confirming previous studies in this area [16-18]. At our institution the majority of patients with minor musculoskeletal injuries are seen and treated by junior ED clinicians. In departments where the proportion of middle grade and senior clinicians is higher, the overall false positive fracture diagnosis rate is likely to be lower.

Despite the inherent limitations of this study, it has involved the close examination of a large cohort of outpatients referred to fracture clinic and identified a significant difference between two commonly used fracture data sources employed in the fracture epidemiology literature. We believe it is the first study to attempt a comparison of this type.

Other research methods described in the literature have included the use of patient questionnaires, insurance company data, and the GPRD. Donaldson et al. [4] relied upon a patient questionnaire to estimate overall fracture incidence in the population. This type of methodology suffers from patient recall bias [19-21], but had the advantage of including fractures that are often treated by the family physician (e.g., osteoporotic vertebral body fractures). Brinker and O'Connor [5] obtained insurance company data in an attempt to estimate the incidence of fractures in Texas, USA. Importantly, uninsured individuals were not included.

The GPRD was used by van Staa and colleagues in an attempt to define fractures patterns in England and Wales 
TABLE 3: The PPV of ED fracture subtype diagnoses. The bold number illustrates the overall PPV of all referred ED fracture cases. The italic cells represent the subtype diagnoses with a statistically significant greater or lesser PPV than the average.

\begin{tabular}{|c|c|c|c|c|c|}
\hline Fracture subtype & Total & Correct $(n)$ & Incorrect $(n)$ & PPV (\%) & $P$ value** \\
\hline Radius and ulna & 2 & 2 & 0 & 100.0 & 0.400 \\
\hline Ulna diaphysis & 22 & 21 & 1 & 95.5 & 0.021 \\
\hline Clavicle & 283 & 261 & 22 & 92.2 & $<0.0001$ \\
\hline Toe & 111 & 102 & 9 & 91.9 & $<0.0001$ \\
\hline Prox humerus & 374 & 342 & 32 & 91.4 & $<0.0001$ \\
\hline Humerus diaphysis & 31 & 27 & 4 & 87.1 & 0.092 \\
\hline$M C$ & 715 & 614 & 101 & 85.9 & $<0.0001$ \\
\hline Radius diaphysis & 7 & 6 & 1 & 85.7 & 0.474 \\
\hline$M T$ & 418 & 358 & 60 & 85.6 & $<0.0001$ \\
\hline Distal radius & 1079 & 895 & 184 & 82.9 & $<0.0001$ \\
\hline Finger & 788 & 623 & 165 & 79.1 & $<0.0001$ \\
\hline Ankle & 474 & 364 & 110 & 76.8 & 0.124 \\
\hline Prox ulna & 28 & 21 & 7 & 75.0 & 0.887 \\
\hline Patella & 23 & 17 & 6 & 73.9 & 0.992 \\
\hline Overall & & & & 73.8 & \\
\hline Spine & 11 & 8 & 3 & 72.7 & 0.934 \\
\hline Distal tibia & 17 & 12 & 5 & 70.6 & 0.762 \\
\hline Fibula & 40 & 28 & 12 & 70.0 & 0.581 \\
\hline Scapula & 32 & 20 & 12 & 62.5 & 0.144 \\
\hline Prox radius & 342 & 208 & 134 & 60.8 & $<0.0001$ \\
\hline Distal ulna & 54 & 32 & 22 & 59.3 & 0.014 \\
\hline Calcaneus & 27 & 14 & 13 & 51.9 & 0.009 \\
\hline Prox tibia & 29 & 15 & 14 & 51.7 & 0.007 \\
\hline Distal femur & 4 & 2 & 2 & 50.0 & 0.278 \\
\hline Pelvis & 8 & 4 & 4 & 50.0 & 0.125 \\
\hline Prox femur & 8 & 4 & 4 & 50.0 & 0.125 \\
\hline Talus & 22 & 11 & 11 & 50.0 & 0.011 \\
\hline Tibia diaphysis & 4 & 2 & 2 & 50.0 & 0.278 \\
\hline Distal humerus & 30 & 12 & 18 & 40.0 & $<0.0001$ \\
\hline Midfoot & 45 & 18 & 27 & 40.0 & $<0.0001$ \\
\hline Carpus & 666 & 161 & 505 & 24.2 & $<0.0001$ \\
\hline Prox radius and ulna & 0 & 0 & 0 & 0.0 & $\mathrm{n} / \mathrm{a}$ \\
\hline
\end{tabular}

$* *$ Chi-square tests.

TABLE 4: Independent variables predictive of a correct ED injury type diagnosis. The odds ratios (Exp(B)) and their 95\% CIs are shown.

\begin{tabular}{|c|c|c|c|c|}
\hline \multirow{2}{*}{ Variable } & \multirow{2}{*}{$\operatorname{Exp}(B)$} & \multicolumn{2}{|c|}{$95 \%$ CI for $\operatorname{Exp}(B)$} & \multirow{2}{*}{$P$ value } \\
\hline & & Lower & Upper & \\
\hline Age & 1.01 & 1.01 & 1.02 & $<0.0001$ \\
\hline Male gender & 1.28 & 1.13 & 1.45 & $<0.0001$ \\
\hline Consultant & 1.31 & 1.00 & 1.70 & 0.048 \\
\hline SHO & 0.85 & 0.75 & 0.96 & 0.009 \\
\hline Ortho & 4.31 & 2.56 & 7.24 & $<0.0001$ \\
\hline ED disloc Dx & 0.16 & 0.08 & 0.30 & $<0.0001$ \\
\hline ED fracture Dx & 0.04 & 0.02 & 0.07 & $<0.0001$ \\
\hline ED other Dx & 0.03 & 0.02 & 0.06 & $<0.0001$ \\
\hline ED rupture Dx & 0.06 & 0.03 & 0.12 & $<0.0001$ \\
\hline
\end{tabular}


[13]. This national database comprises the computerised medical records of a large number of participating general practitioners, and is widely used in epidemiological research. In more recent years, the GPRD has proved a popular source of fracture data as researchers have attempted to identify risk factors for fracture in various patient groups. As an illustration of its popularity, a search of the recent fracture literature was undertaken using the Ovid MEDLINE search engine. From 2004 to 2008, 26 peer-reviewed studies were found containing "fracture(s)" in the title, and "general practice research database" as a keyword. Five studies dealt with the paediatric population [22-26], while the remaining 21 studies analysed adult fractures [27-47].

The GPRD has been reportedly validated [48-50], with a true positive rate ranging from $70 \%$ to $95 \%$ depending on the diagnosis or disease of interest. However, there is very little information in the literature regarding the validity of GPRD skeletal fracture data. The GPRD derives its fracture data from two sources: inpatient fracture data are derived from secondary care discharge letters, and outpatient fracture data are obtained directly from ED discharge records. Van Staa and colleagues, in 2000, analysed hip fractures in the GPRD [51]. They reported that $90.7 \%$ of GPRD entries were confirmed as accurate by the general practitioner, and $86.5 \%$ were confirmed by secondary care discharge letter. To our knowledge, no such data exist for fractures treated on an outpatient basis.

The results of this study highlight the potential error that epidemiologists might expect to encounter if obtaining fracture data from the ED or GPRD. Where possible, we believe future epidemiological fracture research should make use of data obtained from orthopaedic departments in order to minimise the potential error in fracture ascertainment.

\section{Conflict of Interests}

The authors have no conflicts of interests to declare.

\section{References}

[1] P. Cummings, T. D. Koepsell, and B. A. Mueller, "Methodological challenges in injury epidemiology and injury prevention research," Annual Review of Public Health, vol. 16, pp. 381400, 1995.

[2] N. J. Barton, "Twenty questions about scaphoid fractures," Journal of Hand Surgery, vol. 17, no. 3, pp. 289-310, 1992.

[3] C. Gäbler, C. Kukla, M. J. Breitenseher, S. Trattnig, and V. Vécsei, "Diagnosis of occult scaphoid fractures and other wrist injuries: are repeated clinical examinations and plain radiographs still state of the art?" Langenbeck's Archives of Surgery, vol. 386, no. 2, pp. 150-154, 2001.

[4] L. J. Donaldson, I. P. Reckless, S. Scholes, J. S. Mindell, and N. J. Shelton, "The epidemiology of fractures in England," Journal of Epidemiology and Community Health, vol. 62, no. 2, pp. 174180, 2008.

[5] M. R. Brinker and D. P. O'Connor, “The incidence of fractures and dislocations referred for orthopaedic services in a capitated population," Journal of Bone and Joint Surgery A, vol. 86, no. 2, pp. 290-297, 2004.
[6] C. M. Court-Brown, S. A. Aitken, D. Forward et al., "The epidemiology of fractures," in Rockwood and Green's Fractures in Adults, R. W. Bucholz, C. M. Court-Brown, J. D. Heckman et al., Eds., pp. 53-84, Lippincott Williams \& Wilkins, Philadelphia, Pa, USA, 7th edition, 2010.

[7] C. M. Court-Brown and B. Caesar, "Epidemiology of adult fractures: a review," Injury, vol. 37, no. 8, pp. 691-697, 2006.

[8] B. R. Singer, G. J. McLauchlan, C. M. Robinson, and J. Christie, "Epidemiology of fractures in 15,000 adults: the influence of age and gender," Journal of Bone and Joint Surgery B, vol. 80, no. 2, pp. 243-248, 1998.

[9] L. J. Donaldson, A. Cook, and R. G. Thomson, "Incidence of fractures in a geographically defined population," Journal of Epidemiology and Community Health, vol. 44, no. 3, pp. 241245, 1990.

[10] A. Johansen, R. J. Evans, M. D. Stone, P. W. Richmond, S. V. Lo, and K. W. Woodhouse, "Fracture incidence in England and Wales: a study based on the population of Cardiff," Injury, vol. 28, no. 9-10, pp. 655-660, 1997.

[11] Y. Sahlin, "Occurrence of fractures in a defined population: a 1-year study," Injury, vol. 21, no. 3, pp. 158-160, 1990.

[12] D. Fife and J. I. Barancik, "Northeastern Ohio trauma study III: incidence of fractures," Annals of Emergency Medicine, vol. 14, no. 3, pp. 244-248, 1985.

[13] T. P. van Staa, E. M. Dennison, H. G. M. Leufkens, and C. Cooper, "Epidemiology of fractures in England and Wales," Bone, vol. 29, no. 6, pp. 517-522, 2001.

[14] General Register Office for Scotland, "Mid-2008 population estimates by sex and age," 2010, http://www.gro-scotland.gov .uk/files2/stats/gros-mid-2008-population-estimates-scotland-population-estimates-by-sex-age-and-administrativearea/j1075009.htm.

[15] S. E. Campbell, M. K. Campbell, J. M. Grimshaw, and A. E. Walker, "A systematic review of discharge coding accuracy," Journal of Public Health, vol. 23, no. 3, pp. 205-211, 2001.

[16] R. J. Derksen, F. C. Bakker, E. S. M. de Lange-de Klerk et al., "Specialized emergency nurses treating ankle and foot injuries: a randomized controlled trial," The American Journal of Emergency Medicine, vol. 25, no. 2, pp. 144-151, 2007.

[17] M. Sakr, J. Angus, J. Perrin, C. Nixon, J. Nicholl, and J. Wardrope, "Care of minor injuries by emergency nurse practitioners or junior doctors: a randomised controlled trial," The Lancet, vol. 354, no. 9187, pp. 1321-1326, 1999.

[18] A. Wilson and F. Shifaza, "An evaluation of the effectiveness and acceptability of nurse practitioners in an adult emergency department," International Journal of Nursing Practice, vol. 14, no. 2, pp. 149-156, 2008.

[19] P. Jenkins, G. Earle-Richardson, D. T. Slingerland, and J. May, "Time dependent memory decay," American Journal of Industrial Medicine, vol. 41, no. 2, pp. 98-101, 2002.

[20] D. Lilienfeld and P. Stolley, Foundations of Epidemiology, Oxford University Press, New York, NY, USA, 1994.

[21] K. Rothman, Epidemiology: An Introduction, Oxford University Press, New York, NY, USA, 2002.

[22] J. M. Burnham, J. Shults, R. Weinstein, J. D. Lewis, and M. B. Leonard, "Childhood onset arthritis is associated with an increased risk of fracture: a population based study using the general practice research database," Annals of the Rheumatic Diseases, vol. 65, no. 8, pp. 1074-1079, 2006.

[23] C. Cooper, E. M. Dennison, H. G. M. Leufkens, N. Bishop, and T. P. van Staa, "Epidemiology of childhood fractures in Britain: a study using the general practice research database," Journal of Bone and Mineral Research, vol. 19, no. 12, pp. 1976-1981, 2004. 
[24] W. Högler, G. Wehl, T. van Staa, B. Meister, A. Klein-Franke, and G. Kropshofer, "Incidence of skeletal complications during treatment of childhood acute lymphoblastic leukemia: comparison of fracture risk with the general practice research database," Pediatric Blood and Cancer, vol. 48, no. 1, pp. 21-27, 2007.

[25] R. G. Schlienger, S. S. Jick, and C. R. Meier, "Inhaled corticosteroids and the risk of fractures in children and adolescents," Pediatrics, vol. 114, no. 2, pp. 469-473, 2004.

[26] T. P. van Staa, N. Bishop, H. G. M. Leufkens, and C. Cooper, "Are inhaled corticosteroids associated with an increased risk of fracture in children?" Osteoporosis International, vol. 15, no. 10, pp. 785-791, 2004.

[27] K. M. Abel, H. F. Heatlie, L. M. Howard, and R. T. Webb, "Sex- and age-specific incidence of fractures in mental illness: a historical, population-based cohort study," Journal of Clinical Psychiatry, vol. 69, no. 9, pp. 1398-1403, 2008.

[28] A. M. Gallagher, S. Rietbrock, M. Olson, and T. P. van Staa, "Fracture outcomes related to persistence and compliance with oral bisphosphonates," Journal of Bone and Mineral Research, vol. 23, no. 10, pp. 1569-1575, 2008.

[29] J. A. Kaye and H. Jick, "Proton pump inhibitor use and risk of hip fractures in patients without major risk factors," Pharmacotherapy, vol. 28, no. 8, pp. 951-959, 2008.

[30] N. R. Lewis, R. F. A. Logan, R. B. Hubbard, and J. West, "No increase in risk of fracture, malignancy or mortality in dermatitis herpetiformis: a cohort study," Alimentary Pharmacology and Therapeutics, vol. 27, no. 11, pp. 1140-1147, 2008.

[31] C. Meier, M. E. Kraenzlin, M. Bodmer, S. S. Jick, H. Jick, and C. R. Meier, "Use of thiazolidinediones and fracture risk," Archives of Internal Medicine, vol. 168, no. 8, pp. 820-825, 2008.

[32] I. Wilting, F. de Vries, B. M. K. S. Thio et al., "Lithium use and the risk of fractures," Bone, vol. 40, no. 5, pp. 1252-1258, 2007.

[33] T. P. van Staa, P. Geusens, B. Zhang, H. G. M. Leufkens, A. Boonen, and C. Cooper, "Individual fracture risk and the costeffectiveness of bisphosphonates in patients using oral glucocorticoids," Rheumatology, vol. 46, no. 3, pp. 460-466, 2007.

[34] F. de Vries, P. C. Souverein, C. Cooper, H. G. M. Leufkens, and T. P. van Staa, "Use of $\beta$-blockers and the risk of hip/femur fracture in the United Kingdom and The Netherlands," Calcified Tissue International, vol. 80, no. 2, pp. 69-75, 2007.

[35] L. Howard, G. Kirkwood, and M. Leese, "Risk of hip fracture in patients with a history of schizophrenia," The British Journal of Psychiatry, vol. 190, pp. 129-134, 2007.

[36] Y. X. Yang, J. D. Lewis, S. Epstein, and D. C. Metz, "Longterm proton pump inhibitor therapy and risk of hip fracture," JAMA, vol. 296, no. 24, pp. 2947-2953, 2006.

[37] M. Solaymani-Dodaran, T. R. Card, G. P. Aithal, and J. West, "Fracture risk in people with primary biliary cirrhosis: a population-based cohort study," Gastroenterology, vol. 131, no. 6, pp. 1752-1757, 2006.

[38] T. P. van Staa, P. Geusens, J. W. J. Bijlsma, H. G. M. Leufkens, and C. Cooper, "Clinical assessment of the long-term risk of fracture in patients with rheumatoid arthritis," Arthritis and Rheumatism, vol. 54, no. 10, pp. 3104-3112, 2006.

[39] P. C. Souverein, D. J. Webb, J. G. Weil, T. P. van Staa, and A. C. G. Egberts, "Use of antiepileptic drugs and risk of fractures: case-control study among patients with epilepsy," Neurology, vol. 66, no. 9, pp. 1318-1324, 2006.

[40] G. W. K. Hugenholtz, E. R. Heerdink, T. P. van Staa, W. A. Nolen, and A. C. G. Egberts, "Risk of hip/femur fractures in patients using antipsychotics," Bone, vol. 37 , no. 6, pp. 864870, 2005.
[41] F. de Vries, T. P. van Staa, M. S. G. M. Bracke, C. Cooper, H. G. M. Leufkens, and J. W. J. Lammers, "Severity of obstructive airway disease and risk of osteoporotic fracture," European Respiratory Journal, vol. 25, no. 5, pp. 879-884, 2005.

[42] T. P. van Staa, P. Geusens, H. A. P. Pols, C. De Laet, H. G. M. Leufkens, and C. Cooper, "A simple score for estimating the long-term risk of fracture in patients using oral glucocorticoids," QJM, vol. 98, no. 3, pp. 191-198, 2005.

[43] P. C. Souverein, D. J. Webb, H. Petri, J. Weil, T. P. van Staa, and T. Egberts, "Incidence of fractures among epilepsy patients: a population-based retrospective cohort study in the general practice research database," Epilepsia, vol. 46, no. 2, pp. 304310, 2005.

[44] J. A. Kaye and H. Jick, "Epidemiology of lower limb fractures in general practice in the United Kingdom," Injury Prevention, vol. 10, no. 6, pp. 368-374, 2004.

[45] R. G. Schlienger, M. E. Kraenzlin, S. S. Jick, and C. R. Meier, "Use of $\beta$-blockers and risk of fractures," JAMA, vol. 292, no. 11 , pp. 1326-1332, 2004.

[46] D. J. Torgerson, D. Sykes, S. Puffer, P. Brown, and C. Cooper, "Pharmaceutical treatment of symptomatic vertebral fractures in primary care," Annals of the Rheumatic Diseases, vol. 63, no. 7, pp. 853-856, 2004.

[47] T. Card, J. West, R. Hubbard, and R. F. A. Logan, "Hip fractures in patients with inflammatory bowel disease and their relationship to corticosteroid use: a population based cohort study," Gut, vol. 53, no. 2, pp. 251-255, 2004.

[48] H. Jick, S. S. Jick, and L. E. Derby, "Validation of information recorded on general practitioner based computerised data resource in the United Kingdom," BMJ, vol. 302, no. 6779, pp. 766-768, 1991.

[49] H. Jick, S. Jick, L. E. Derby, C. Vasilakis, M. W. Myers, and C. R. Meier, "Calcium-channel blockers and risk of cancer," The Lancet, vol. 349, no. 9051, pp. 525-528, 1997.

[50] A. Ruigómez, L. A. García Rodríguez, M. A. Wallander, S. Johansson, H. Graffner, and J. Dent, "Natural history of gastro-oesophageal reflux disease diagnosed in general practice," Alimentary Pharmacology and Therapeutics, vol. 20, no. 7, pp. 751-760, 2004.

[51] T. P. van Staa, L. Abenhaim, C. Cooper, B. Zhang, and H. G. Leufkens, "The use of a large pharmacoepidemiological database to study exposure to oral corticosteroids and risk of fractures: validation of study population and results," Pharmacoepidemiology \& Drug Safety, vol. 9, no. 5, pp. 359-366, 2000. 


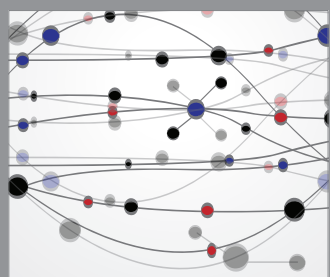

The Scientific World Journal
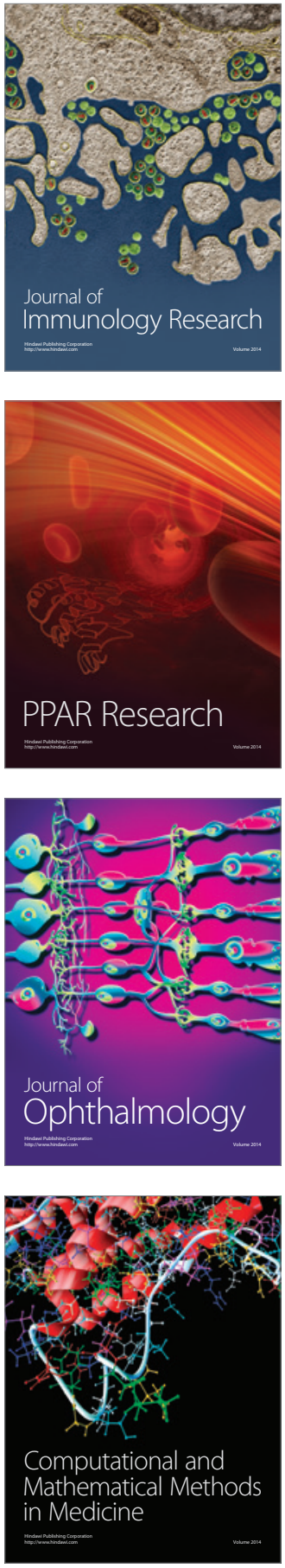

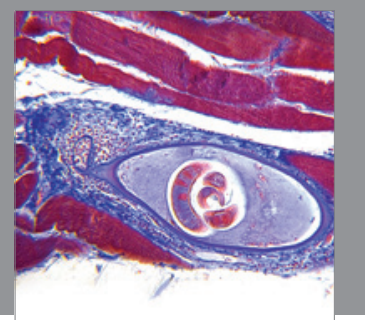

Gastroenterology

Research and Practice
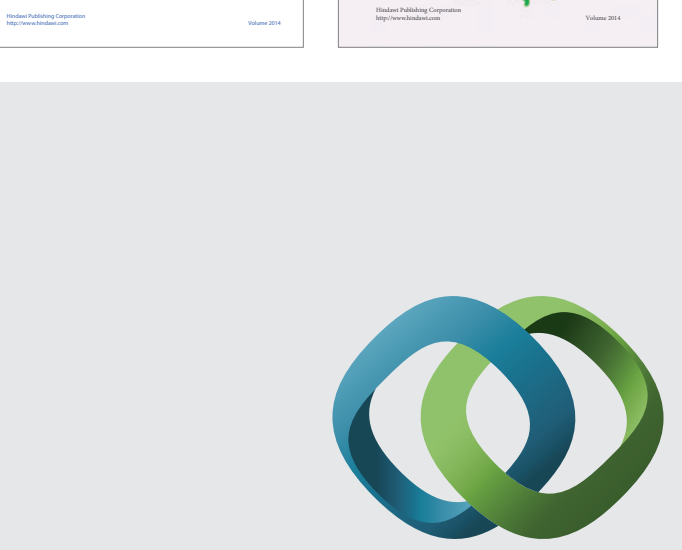

\section{Hindawi}

Submit your manuscripts at

http://www.hindawi.com
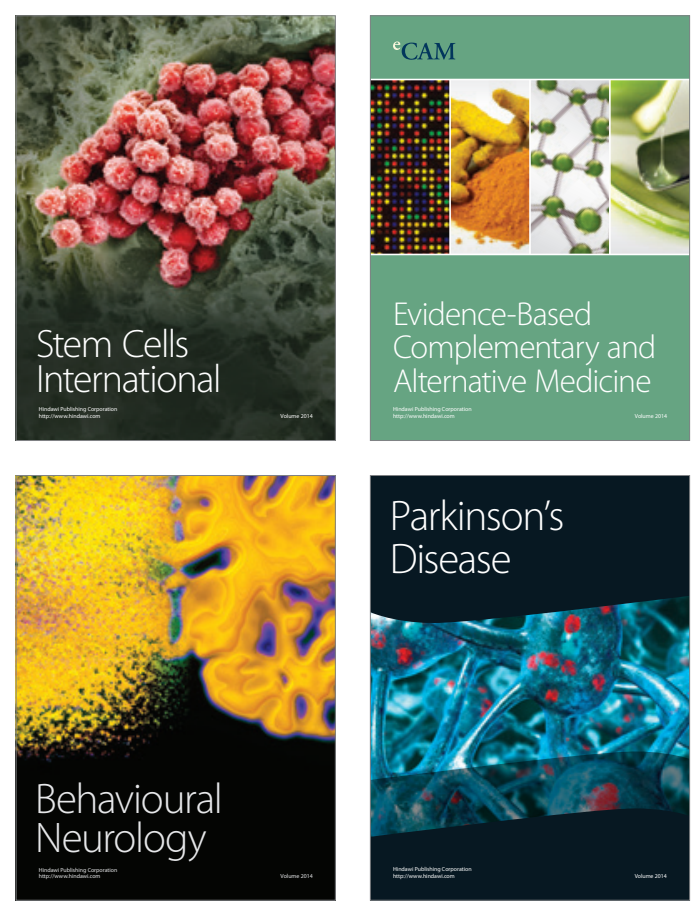

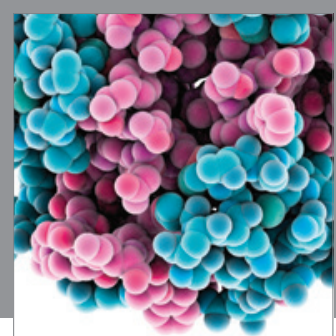

Journal of
Diabetes Research

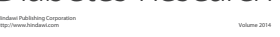

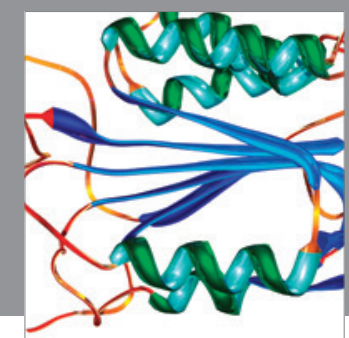

Disease Markers
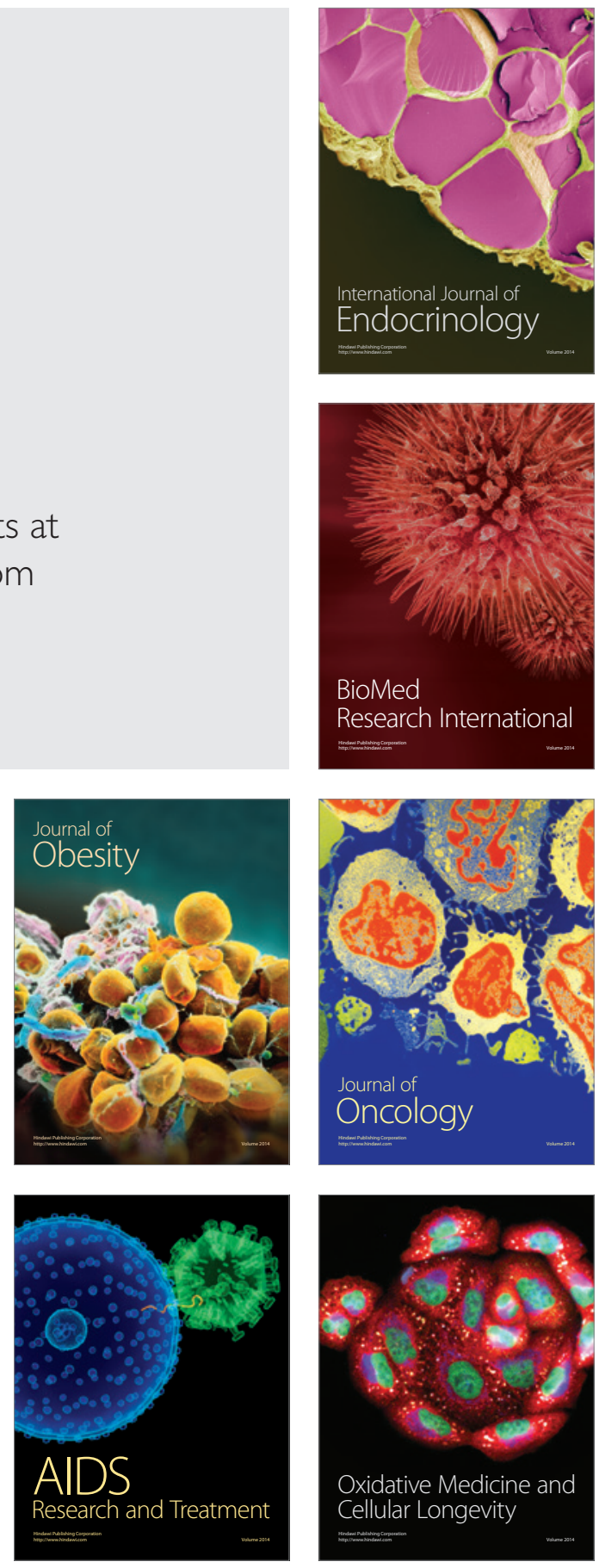